\title{
JEAN-LUC GODARD E A EDUCAÇÃO: o exemplo de La Chinoise (A Chinesa, 1967)
}

\section{JAILSON DIAS CARVALHO}

Doutor em História (Universidade Federal de Uberlândia, 2017). Professor de História da rede estadual de Ensino de Uberlândia. Pesquisa sobre cinema e história, atuando, principalmente, em historiografia clássica do cinema brasileiro; história, cinema e modernidade.

ORCID: https://orcid.org/0000-0003-4619-9468. E-mail: carvalho_jailson@yahoo.com.br 
JEAN-LUC GODARD E A EDUCAÇÃO: o exemplo de La Chinoise (A Chinesa, 1967)

Decorridos cerca de cinco décadas após o seu lançamento em 1967, a película La Chinoise (A Chinesa), de Jean-Luc Godard, não cessou de produzir efeito junto aos espectadores e admiradores da obra do cineasta francês. Nesse sentido, a película La Chinoise, compreende determinados elementos em seu interior que sinalizam para o fato de que a educação, entendida como um processo de formação dos indivíduos, parece ser manejada, tendo por objetivo impelir, insuflar os integrantes da célula de estudos Aden Arábia à ação revolucionária. Nesse tocante, o manuseio de textos canônicos do marxismo (de Mao Zedong, dentre outros), proclamados em voz alta, indicaria determinados procedimentos de ensino-aprendizagem, que, conjugados a determinados métodos e instrumentos, tais como o uso da lousa, cartazes, esquetes, traduzem formas de ensino que contribuiriam para que os militantes propiciem a revolução. Desta forma, conceitos como gêneros do discurso provenientes de Mikhail Bakhtin e gêneros de atividade, tematizado por Daniel Faïta, tornam-se fundamentais para entender La Chinoise e sua relação com a educação..

Palavras chave: Educação. La Chinoise (A Chinesa). Gêneros do Discurso; Gêneros de Atividade; JeanLuc Godard.

\section{JEAN-LUC GODARD AND EDUCATION: the case of La Chinoise (The Chinese, 1967)}

Around five decades after the release of La Chinoise (The Chinese) in 1967, by Jean-Luc Godard, the movie has never stopped affecting viewers and admirers of the French moviemaker's work. La Chinoise has certain intern elements that point out to the fact that education, understood as a process of forming individuals, seems to be managed with the aim to prompt and instigate the members of the Aden Arabia cell to revolution. In the movie, handling canonical Marxist texts (by Mao Zedong, among others), proclaimed out loud, seems to indicate certain teaching-learning procedures, which, along with some methods and instruments such as the use of a board, posters, and sketches, translate forms of teaching that could contribute to militants to promote a revolution. Thus, concepts like speech genre, by Mikhail Bakhtin, and professional genre, by Daniel Faïta, are essential to understand La Chinoise and its relation with education.

Keywords: Education; La Chinoise (The Chinese); speech genres; professional genres; Jean-Luc Godard. 


\section{JEAN-LUC GODARD Y LA EDUCACIÓN: el ejemplo de La Chinoise (La China, 1967)}

A casi cinco décadas de su estreno en 1967, la película La Chinoise (La China) de Jean-Luc Godard, no ha dejado de surtir efecto entre los espectadores y admiradores de la obra del cineasta francés. La película La Chinoise contiene ciertos elementos que señalan el hecho de que la educación, entendida como un proceso de formación de los individuos, parece ser manipulada con el objetivo de impulsar e inducir a los integrantes de la célula de estudios Aden Arábia a la acción revolucionaria. En este contexto, el manejo de los textos canónicos del marxismo (de Mao Tse-Tung, entre otros) proclamados en voz alta, indicaría determinados procesos de enseñanza-aprendizaje que, conjugados con determinados métodos y herramientas tales como el uso del pizarrón, afiches y sketches, reflejarían formas de enseñanza que contribuirían a que los militantes propicien la revolución. Por consiguiente, los conceptos como géneros del discurso de Mikhail Bakhtin y géneros de la actividad, tematizado por Daniel Faïta, se vuelven fundamentales para entender La Chinoise y su relación con la educación.

Palabras-clave: educación. La Chinoise (La China). Géneros del discurso. Géneros de la actividad. 


\section{JEAN-LUC GODARD E A EDUCAÇÃO: o exemplo de La Chinoise (A Chinesa, 1967)}

\section{Introdução}

A partir da segunda metade dos anos noventa, o cineasta Jean-Luc Godard atraiu o entusiasmo de uma constelação de intelectuais que transitam por diversas áreas, dentre eles, historiadores, sociólogos e críticos de literatura em diversas partes do mundo.

A esse interesse, credita-se o lançamento de seu filme Histoire(s) du cinéma (1998), no Brasil, História(s) do cinema, que granjeou uma série de artigos e dissertações ${ }^{1}$. Na esteira desse fluxo de investigação, um conjunto expressivo das obras de Jean-Luc Godard foi exibido no Brasil em uma mostra cinematográfica consagrada para esse fim em três capitais brasileiras, São Paulo, Brasília e Rio de Janeiro, durante o ano de 2015 e início de 2016, o que revela o papel preponderante que ele tem assumido na atualidade, combinado a um maior conhecimento de sua biografia, que contribui para esclarecer aspectos de sua trajetória pessoal e artística² .

Contudo, o período de sua trajetória que nos interessa diz respeito à produção godardiana entendida como cinema político, ou seja, a produção que aborda a relação que o cineasta estabelece entre o cinema e a sociedade. A obra fílmica A chinesa é imediatamente anterior à inserção de Godard no grupo Dziga Vertov³. A experiência com esse grupo tinha como

\footnotetext{
${ }^{1} \mathrm{Na}$ Argentina, podemos citar a obra conjunta que trata sobre a película História(s) do cinema (1998), de Jean-Luc Godard, e, no Brasil, cabe referir-nos à edição organizada por José Francisco Serafim, que teve a mesma preocupação. Ver: SARLO, Beatriz et al. Jean-Luc Godard: el pensamiento del cine, cuatro miradas sobre Histoire(s) du cinéma. Buenos Aires: Paidós, 2003. e SERAFIM, José Francisco (Org.). Godard, imagens e memórias: reflexões sobre História(s) do cinema. Salvador: EDUFBA, 2011.

${ }^{2}$ A respeito do projeto Retrospectiva Jean-Luc Cinema Godard no Brasil, confira: PUPPO, Eugenio. ARAÚJO, Mateus (Org.). Godard inteiro ou o mundo em pedaços. São Paulo: Centro Cultural do Banco do Brasil, 2015. Sobre a biografia de Jean-Luc Godard, que recebeu a colaboração dos familiares dele com o envio de fotos e documentos e notabilizou-se pelo caráter ampliado da pesquisa sobre a vida de Godard, ver: BAECQUE, Antoine de. Godard: biographie. Paris: Grasset, 2010b.

${ }^{3}$ Cabe frisar que a narrativa da fita A Chinesa trata sobre um grupo de militantes jovens de esquerda que alugam um apartamento durante uma temporada de férias estudantis e, nesse curto período, participam de um grupo de estudos sobre aspectos que envolvem a sua formação tendo como horizonte a revolução. Membros de uma célula marxista-leninista, intitulada de Aden-Arábia, alguns desses ativistas lecionam aulas teóricas, e todos praticam exercícios ginásticos. Sua formação prevê a encenação de episódios da atualidade e, como prática, o terrorismo torna-se o meio para se alcançar a revolução.
} 
características produzir filmes coletivamente e intervir nas reivindicações imediatas dos atores sociais em conflito, estabelecendo discussões sobre as lutas de classes, o papel do movimento estudantil, dentre outros temas. O grupo contou com a participação, por exemplo, de Jean-Pierre Gorin e Godard. Cabe assinalar que Jean-Pierre Gorin e Jean Baby, "redator chefe de Economie et Politique, antigo responsável do PCF [...] e um dos primeiros membros do comitê central comunista a se declarar maoísta" (BAECQUE, 2010b, p. 353, tradução minha), guiaram Jean-Luc Godard no maoísmo francês. No entanto, desse contato, foi unicamente Godard que formulou a narrativa de A chinesa (BAECQUE, 2010b, p. 353).

Portanto, a experiência de concretização do filme pelo diretor congregava um alcance estético e, ao mesmo tempo, promovia ou delineava os atores que ele acreditava estarem em luta ou serem capazes de dar impulso à mudança social. Em suma, A chinesa assegurava em seu interior uma proposta artística e fazia um exame sobre a participação e a intervenção de várias forças políticas em seu presente imediato. Esse diagnóstico proposto por Godard no plano do cinema envidou críticas expressas à primazia cinematográfica estadunidense no mundo e, no plano da política mais geral no continente europeu, sobretudo na França, estabeleceu questionamentos sobre a atuação do Partido Comunista Francês (PCF), que se atava a uma proposta de coexistência pacífica, tinha como fiador o Partido Comunista da União Soviética (PCUS) e previa um alinhamento diplomático-político internacional de convivência e reconhecimento dos Estados Unidos como potência bélica no mundo capitalista.

Ao encenar determinados atores políticos capazes de promover rupturas, como, por exemplo, a China, o maoísmo e a Revolução Cultural Proletária deflagrada naquele país, ou mesmo ao aludir ao protagonismo de Ernesto Che Guevara e a Fidel Castro, o cineasta desenvolveu, com A chinesa, um produto, não é por demais insistir, artístico - não isento de ironia - com características definidas de intervenção política na órbita da autoria no cinema. Essa atitude atraiu a atenção de determinado público, já familiarizado com sua temática, e também de atores que exerciam uma participação social premente entre os anos finais da década de sessenta. Por essas razões, a obra e esse período interessaram-nos de perto, sobretudo a sua relação com a educação ${ }^{4}$.

\footnotetext{
${ }^{4}$ Na obra Godard e a Educação (2013), que acreditamos ser de inspiração para enveredarmos por este tópico em La Chinoise, emergem os seguinte temas concernentes à obra cinematográfica de Jean-Luc Godard: a existência ou não de um pegadogia godardiana das imagens, aportes que sinalizam para uma vinculação entre a educação e o ofício de criação cinematográfica sendo que procuraremos relacionar tais contribuições com a apreciação de uma reflexão sobre a possibilidade de La Chinoise educar ou não.
} 
Nesse prisma, incumbe descrever as vicissitudes decorrentes da cinefilia francesa ${ }^{5}$, fatores que, acredita-se, intensificaram as posições de esquerda do diretor nos anos finais da década de sessenta e contribuem para aproximarmos de nosso objeto.

Nesse cenário, dois episódios relacionados com a cinefilia francesa, entre os anos de 1966 e 1968, merecem destaque, pois envolveram um expressivo número de indivíduos em torno da interdição da película A religiosa (1965), de Jacques Rivette, e da destituição de Henri Langlois da Cinemateca Francesa ${ }^{6}$. Trataremos somente da interdição do filme, entretanto, cabe destacar que tais acontecimentos evidenciaram a "tomada de consciência política dos cinéfilos", de acordo com Antoine de Baecque (2010a, p. 389; 2010b, p. 391), dentre os quais se inclui Jean-Luc Godard, que teve um papel preponderante durante esses eventos

No primeiro deles, é preciso ter em conta que trechos do filme A religiosa já haviam sido exibidos na televisão francesa sem que houvesse contestação quanto a isso. A Comissão de Controle dos Filmes, inclusive, por duas vezes pronunciara-se favorável nesse sentido. No entanto, diversas petições circulavam no meio católico, sobretudo nas escolas particulares, contrárias a sua exibição. Depois de muita pressão, multiplicaram-se os ataques ao filme, que acabou sendo proibido pelo Ministro da Informação, Yvon Bourges, em 1º de abril de 1966.

Portanto, a proibição de veiculação da película foi, notadamente, política, e a reação dos cinéfilos face a ela denotou uma mudança na cinefilia, visto que exigiu um enfrentamento com o poder político. O descompasso entre a expectativa frustrada e a proibição implica, pois, um novo horizonte, abalizado pelo confronto para liberação do filme na prática da cinefilia francesa.

O episódio de interdição da película mobilizou Jean-Luc Godard. Ele teve uma atuação marcante, promovendo a coleta de assinaturas de personalidades contrárias ao veto do ministro e pronunciando-se na imprensa a favor da liberação do filme.

\footnotetext{
${ }^{5} \mathrm{Na}$ obra Godard e a Educação (2013), que acreditamos ser de inspiração para enveredarmos por este tópico em La Chinoise, emergem os seguinte temas concernentes à obra cinematográfica de Jean-Luc Godard: a existência ou não de um pegadogia godardiana das imagens, aportes que sinalizam para uma vinculação entre a educação e o ofício de criação cinematográfica sendo que procuraremos relacionar tais contribuições com a apreciação de uma reflexão sobre a possibilidade de La Chinoise educar ou não.

${ }^{6}$ Muito embora a mobilização a favor de Henri Langlois tenha ocorrido após a produção do filme A chinesa, a atuação em prol de seu retorno à direção da Cinemateca Francesa de parte expressiva da cinefilia na França foi um dos fatores que contribuiu para fomentar a participação política não somente de Jean-Luc Godard, mas também de François Truffaut e dos membros da redação dos Cahiers du cinéma (BAECQUE, 2010a, p. 391).
} 
Nesse tocante, a intensa mobilização da cinefilia francesa que decorreu após a interdição do filme A religiosa contribuiu, por fim, para que o veto fosse derrubado e a película pode ser exibida em 26 de julho de 1967 nas salas francesas. Dessa experiência, resultou uma cinefilia mais destemida e politizada e um cineasta, como Jean-Luc Godard, combativo e atuante, e tal desejo de intervenção pode ser percebido na forma como se organiza, na película La Chinoise, a educação e a revolução

\subsection{Educação revolucionária em La Chinoise}

O universo instrucional dos indivíduos está presente na fita La Chinoise. Neste aspecto, cabe salientar os elementos que evidenciam tal assertiva na trama narrativa do filme. É preciso notar também se o aspecto de formação que recobre a película é indicador de um caráter recepcional do cineasta Jean-Luc Godard de uma determinada compreensão da educação, cabendo investigar se tais nuances da narrativa da película familiarizam ou conferem ou não uma proximidade do espectador em razão da temática inerente à película La Chinoise.

O início do filme revela o preceito instrutivo de que se serve a narrativa para descrever a trajetória de cinco personagens que alugam um apartamento durante as férias de verão, com o intuito de estudar textos canônicos do marxismo, ou partes de obras da literatura universal, bem como pretendem investigar ou analisar (conforme acepção dos personagens) "situações concretas" (de acordo com o jargão marxista-leninista), como, por exemplo, a guerra do Vietnã, tendo por objetivo intervir nesta situação.

O começo da película é constituído por flashs preambulares, ou de outra forma, pequenas sequências sintéticas que antecedem o desenrolar da fita? Trata-se de sequências cujo tempo máximo não exceda os três segundos. Esse bloco de sequências é constituído por cenas de perfil dos personagens, por fotos de Mao Zedong, Fidel Castro, Vladimir Lênin, Jean-Paul Belmondo, dentre outros, de ações, enfim, na qual estão envolvidas as figuras dramáticas, bem como da capa dos Cahiers marxistes-léninistes. As sequências prosseguem após o aparecimento dos letreiros e obedecem a um princípio de dispersar e confluir.

\footnotetext{
${ }^{7}$ Muito embora a mobilização a favor de Henri Langlois tenha ocorrido após a produção do filme A chinesa, a atuação em prol de seu retorno à direção da Cinemateca Francesa de parte expressiva da cinefilia na França foi um dos fatores que contribuiu para fomentar a participação política não somente de Jean-Luc Godard, mas também de François Truffaut e dos membros da redação dos Cahiers du cinéma (BAECQUE, 2010a, p. 391).
} 
De acordo com Robert Stam (1981), que estabeleceu um estudo sobre o anti-ilusionismo na literatura e no cinema, delineia-se em Pierrot le Fou (O Demônio das onze horas), película de Jean-Luc Godard, uma condição que pode ser observada em muitos filmes do cineasta, sendo tal constatação pertinente para o estudo de La Chinoise, qual seja: a "dispersão das trilhas do filme - imagem, diálogo, ruído, música e legendas" (p. 175). No entender do ensaísta, nas películas do cineasta francês, "recebemos muita informação para assimilar" (176) de uma única vez:

\begin{abstract}
A imagem conta uma história; o diálogo conta outra; o ruído, outra; e a música, uma outra inteiramente diferente. Todos esses elementos são utilizados por Godard em seu ataque coordenado à sensibilidade do espectador e às convenções do realismo. Criando uma sobrecarga sensorial, Godard desorienta e irrita. (STAM, 1981, p. 175-176)
\end{abstract}

Entretanto, o princípio de embaraço que percorre sua obra, pode ser amenizado mediante um percurso, ativado pelo próprio espectador, que consistiria em permitir que cada sentido percorresse seu caminho rumo a uma compreensão do filme. Desta forma, caberia, mesmo, rever o filme diversas vezes, atento, assegura Robert Stam, "uma vez para a imagem, outra para ouvirmos os diálogos, outra para a música, outra para os ruídos de fundo e outra para as cartelas". Por vezes, ainda, constata o autor, "em que os sentidos não só se dispersam uns dos outros, mas também em que cada sentido é solicitado a percorrer diversos caminhos de uma só vez" (STAM, p. 176).

Atento para essas considerações assinaladas por Robert Stam, compete percorrer os letreiros da película La Chinoise, conferindo a eles o estatuto de autonomia face às imagens, à música, aos diálogos, e aos ruídos. Incumbe reconhecer ainda que todas as trilhas do filme a serem citadas guardam a mesma condição de independência entre si, bem como mobilizam a atenção do espectador para o caráter multidirecional da sua relação convergente. Ou, em outros termos, ao mesmo tempo em que as trilhas do filme são independentes e/ou "desorientam e irritam", elas guardam também uma relação de proximidade, assim, distância e/ou recuo e contiguidade e/ou interação tornam-se a tônica que preside a tecitura da fita, condição que, até certo ponto, permite avaliar as partes da película sem que se esteja preso a uma delas separadamente ou não.

Os letreiros iniciais do filme procuram situar o espectador no espaço da ficção da obra cinematográfica. Sobre um fundo preto da tela, as palavras, no centro da tela, inscritas em letra de forma (BIENTÔT/SUR/CET ÉCRAN), sinalizam para um acontecimento que estar por vir. E a utilização do flash preambular torna-se imprescindível, pois cumpre a função de: antecipação das 
ações dos personagens; visualização das fotografias que incidirão na tela, bem como a audição da música-manifesto que acompanha a apresentação do flash.

Predispor o espectador para o universo de ficção da fita La Chinoise torna-se uma característica relevante dessa obra fílmica e, ao mesmo tempo, demonstra o perfil didático dela, no sentido atribuído a esse termo por Regina Célia Cazaux Haydt (2000), segundo a qual a didática seria a "arte do ensino" (p.13, grifo no original). Bem entendido que a didática atual não trataria unicamente do ensino, por parte do professor, mas também da relação de aprendizagem por parte do aluno. Desta forma, caberia demonstrar como se estabelece na película o processo de ensino e aprendizagem da experiência revolucionária, tendo presente que se trata de um dos polos da película na qual se pretende investigar a temática do universo instrucional da política, percebendo, ainda, a relação personagem-espectador que a pressupõe.

Antes, porém, cabe frisar que a atitude instrucional da película La Chinoise e o emprego da tela com lousa por parte de Jean-Luc Godard, durante os anos finais da década de sessenta, foi notado por pensadores franceses ${ }^{8}$. Serge Daney (2007), em texto publicado em sua coletânea de ensaios sobre a "pedagogia godardiana", assinala que, a partir de maio 1968, o cineasta Jean-Luc Godard constatou uma "suspeita" de que a "sociedade [do espetáculo] produz mais imagens e sons do que pode ver e digerir" (p. 107). Constatação bastante curiosa para a uma geração de cineastas autodidatas, de acordo com o ensaísta, que foram também os responsáveis por investirem nesse processo de produção de imagens e para a qual a sala de cinema "tomou o lugar" para eles do ambiente da escola e da família. "A grande suspeita", na acepção de Serge Daney (2007), pressupunha uma atitude na qual era preciso "aprender", e, para aprender, era "preciso ir para a escola". Não precisamente a "escola da vida", mas, constata o autor, "o cinema como escola".

\footnotetext{
${ }^{8}$ Jacques Rancière (2013), em ensaio estabelecido sobre "o vermelho de A Chinesa: política de Godard”, embora não trate diretamente sobre o caráter instrucional desta película, e sim sobre o "marxismo como matéria representada" no filme La Chinoise e o "marxismo como princípio de representação" (p. 147), notou, igualmente, que a fita, imbuída da "pedagogia althusseriana" que prognosticava uma condição de "reapredizagem" de saber "ver, ouvir, falar, ler" os "gestos mais simples da existência", procurava colocar em prática este programa althusseriano em "princípio de mise-en-scène da retórica e da géstica maoísta", nas suas palavras: "O filme trata, portanto, de aprender a ver, ouvir, falar ou ler aquelas frases do Pequeno livro vermelho ou de Pékin information. Mas, também, de aprender a ler com elas, como exemplo qualquer, semelhante às histórias e aos exemplos dos livros de leitura elementares. Trata-se, portanto, de um trabalho sobre o marxismo, com o marxismo, que também é um trabalho do cinema sobre o cinema” (p. 148).
}

P/U] $a$ ì Salvador, v. 4, n. 2, p. 146-168, mai./ago. 2019 
Em 1968, para a facção mais radicalizada - a mais esquerdista - dos cineastas, uma coisa é certa: é preciso aprender a sair das salas de cinema (da cinefilia obscurantista) ou, ao menos, conectá-la a qualquer outra coisa. E, para aprender, é preciso ir à escola. Não exatamente à "escola da vida", mas ao cinema como escola. É assim que Godard e Gorin transformaram o cubo cenográfico em sala de aula; o diálogo do filme em recitação; a voz em off em aula magistral; a filmagem em trabalhos dirigidos; o tema dos filmes em matérias obrigatórias ("o revisionismo", "a ideologia" etc); e o cineasta em diretor da escola, em monitor, bedel. A escola torna-se então o bom lugar, aquele que se afasta do cinema e se aproxima do "real" (um real-a-ser-transformado, claro). É desse espaço que nos chegaram todos os filmes de Godard desde A Chinesa. Em Tout va bien, Número deux e Ici et ailleurs é o apartamento da família que toma o lugar da sala de aula, e a televisão, o do cinema. $\mathrm{O}$ essencial permanece: as pessoas que fazem a lição. (DANEY, 2007, p. 107-108. Grifo no original)

O comentário de Serge Daney permite-nos constatar que a postura, godardiana de encarar a tela do cinema como um local propício para aprender e ensinar, estava presente em seu horizonte cinematográfico, e os recursos cinematográficos disponíveis como a tela, o diálogo do filme, o tema das películas, os letreiros entre as cenas, se aproximaram simbolicamente ao espaço escolar' ${ }^{9}$

Tendo presente essa constatação, temos que o fundo preto na qual as palavras iniciais foram inscritas cumpre a função de uma lousa ou quadro negro. A sala escura de espetáculos na qual se encontra a plateia, torna-se uma sala de aula, e o espectador assume a condição de aluno, palavra que derivada do latim, alumn, significa aquele que "recebe instrução e/ou educação de algum mestre, ou mestres" (FERREIRA, 1986, p. 95).

Entre os letreiros que prosseguem após os flashes preambulares, incluem-se o título do filme e a identificação do diretor, sendo que as cores predominantes destes letreiros são o azul, amarelo e o vermelho, respectivamente (LA CHINOISE/UN FILM DE/J.L GODARD). São, basicamente, as cores primárias que predominam nos letreiros e só aparentemente torna-se um letreiro comum, pois,

\footnotetext{
${ }^{9}$ Jorge Vasconcelos (2008), apoiado em Gilles Deleuze, por sua vez, reconhece a existência de uma "pedagogia da imagem audiovisual" no conjunto das obras cinematográficas de Jean-Luc Godard. De acordo com o pesquisador, esta pedagogia estaria relacionada com o fato de que o cineasta francês buscaria "revelar as tramas de sentido" das imagens. Nas suas palavras: "A pedagogia godardiana da imagem audiovisual pergunta pela revelação das tramas do sentido que toda e qualquer imagem se põe. Não se trata de revelar uma "verdade" por trás (o sentido ideológico), mas, isto sim, trata-se de buscar revelar justamente todo o sentido que habita a imagem. E este procedimento pode ser chamado de uma pedagogia exatamente porque ele insiste em que há algo a ser ensinado, melhor que isto, existe a possibilidade de um pensamento sobre o ensinar em relação a toda e qualquer imagem." (VASCONCELOS, 2008, p. 164, grifo nosso)
} 
à medida que perdura a apresentação geral do filme, mediante as sequências, esta identificação do nome da fita e do diretor se desmembra em várias sílabas, que passam a significar outras palavras como por exemplo: IN= em (inglês, que pode significar na tela a seguir); $\mathrm{LAC}=$ lago; CIA= Agência Central de Inteligência; LOI= lei/norma, e assim sucessivamente ${ }^{10}$.

Trata-se de uma formação de palavras que ocupam o centro da tela, cujo fundo é escuro. Tal procedimento torna-se uma constante ao longo da fita. Um elemento visual encadeia outro elemento. Neste caso, do título do filme surgiram diversas palavras, aparentemente, sem relação com a trama narrativa. Contudo o caráter didático da cena merece destaque, pois procura ensinar algo ao público: de uma palavra engendram-se outras. O surgimento delas na tela delineia o modo demonstrativo que percorre a película La Chinoise e, por sua vez, o caráter didático dela ${ }^{11}$.

\subsection{O procedimento recitativo de La Chinoise}

Após os flashes preambulares e os intertítulos de formação de palavras, surge o personagem Henri (interpretado por Michel Semeniako).

Conhecemos o personagem desta forma: de boina, casaco, blusa amarela, caneta na mão direita. Ele se movimenta e parece dizer a si mesmo o texto. Ninguém mais está na sacada. No entanto, sublinha determinadas palavras que acredita ser importantes. Frisa, de fato, algumas delas. E após ler determinados trechos, adentra-se para o apartamento lendo em voz alta. Essa é

\footnotetext{
${ }^{10}$ Mais exemplos podem ser citados: $\mathrm{CHIE}=$ cagar; $\mathrm{SOI}=\mathrm{si}$; NICE= cidade francesa; OISE= rio lo calizado no norte da França; $\mathrm{SCIE}=$ serra; $\mathrm{CHOSE}=$ coisa; $\mathrm{BIEN}=$ bem; $\mathrm{SUR}=$ em cima de, sobre; TÔT= cedo; $\mathrm{CET}=$ esse. Esta e as demais citações de trechos do filme tiveram como ponto de partida a transcrição da fita, traduzida por Yvonne Costa Ribeiro e publicada na coletânea organizada por Haroldo Barbosa (1968), cotejada com a publicação dos cinco roteiros dos filmes de Jean-Luc Godard (1973), editada pela Alianza Editorial para o espanhol, e pela transcrição do autor deste estudo, confrontada com a versão em DVD de La Chinoise, telecinado direto do negativo original pela Silver Screen Collection (snt.)

${ }^{11}$ Tal modo pode ainda ser verificado na forma pela qual a personagem Véronique tenta explicar à Yvonne a atitude de seu namorado Henri que, aparentemente, refuta a ideia de sair com ela para assistir a uma película, preferindo vender o jornal Guarde Rouge. Véronique procura explicar a postura dele, fazendo uso de alguns exemplos desconexos relacionados com a política: "Porque a política é o ponto de partida... de toda a política, a política é o ponto de partida de toda a ação prática de um partido revolucionário". A forma como diz, os gestos que ela usa (dedo em riste, ou na cabeça tentando explicar algo com exemplos), e o ângulo na qual Véronique está posicionada (de frente e no centro de um cartaz que está na parede na qual crianças chineses estão sentadas em torno de um adulto que fala para eles), indicam um posicionamento professoral de sua parte, e mais: revela um estado em que os personagens do filme estão sempre explicando algo de si, de sua prática, do seu entorno, da sociedade na qual estão envolvidos.
} 
a tônica dos personagens de La Chinoise. A maioria deles declamam o seu discurso em voz alta. Na verdade, recitam-no.

A prática de ler em voz alta, levada a cabo durante a fita, lembra aquela forma de ensino e aprendizagem na qual o indivíduo estudava os textos literários, da gramática, da história e da geografia durante o século XVII. O mais importante na aprendizagem dos alunos, de acordo com Regina Célia Cazaux Haydt (2000, p. 14), era a "repetição de exercícios graduados", que se tornando a cada vez mais difíceis, possibilitariam aos discípulos "executar certos atos complexos, que aos poucos iam se tornando hábitos".

Dessa forma, a "recitação de cor" na acepção da autora, pressupunha um procedimento mediante o qual um professor valia-se de perguntas e respostas que permitiriam aos alunos repetir "correta e adequadamente" os conhecimentos. Tal método ficou conhecido como "catequético". E na cultura ocidental remonta aos gregos: "A palavra catecismo provém do termo grego katechein, que significa "fazer eco". O importante em tal forma de aprendizagem consistiria no fato de que o aluno "reproduzisse literalmente as palavras e frases decoradas" (p. 15).

Tal procedimento converte-se no mote que acompanha os personagens, seja nas cenas individuais, nas quais o objeto é a aprendizagem dos trechos e discursos advindos do marxismo ou nas sequências nas quais o comediante torna-se um mediador da aprendizagem entre os demais.

A título de exemplo cabe-nos destacar o trecho no qual Guilhaume recita em "voz alta" trechos do Pequeno Livro Vermelho ${ }^{12}$. É possível vê-lo transitando pelos cômodos do apartamento declamando, ou apenas escuta-se a sua voz sem que se veja seu corpo na tela ${ }^{13}$.

\footnotetext{
${ }^{12}$ Jacques Aumont (2013), um dos intelectuais franceses entrevistados por Mário Alves Coutinho, na importante obra dedicada ao tema da literatura, o cinema e o cineasta Jean-Luc Godard, reconhece que o discurso político sempre atraiu o interesse do integrante da Nouvelle Vague. O discurso político em Godard nunca significou um gênero pouco representativo da literatura (p. 48), decorre, então, que ele fosse passível de se tornar cinematográfico.

${ }^{13}$ Outro modo de entender o procedimento recitativo em Godard foi exposto por Alain Bergala (2013) em entrevista. De acordo com o ensaísta e pesquisador do cinema, o modo recitativo de Jean-Luc Godard e a sua voz nos filmes adviriam de André Malraux. Uma vez estabelecido o contato com a obra desse escritor, de acordo com Alain Bergala, Godard faz os seus personagens interpretarem da mesma forma que os discursos e personagens do escritor de A condição humana, pois, na sua interpretação, "perdemos o fato de que uma frase nós a dizemos com um certo ritmo, uma certa lentidão, Godard gosta muito desta música. E eu, muitas vezes, nas frases de Godard, ouço Malraux, a maneira de falar de Malraux. Godard procurou muito por atores capazes de fazer isso, hoje. Pois isso é o contrário do natural, ele procurou atores capazes de recitar, declamar. Sua voz [a voz de Godard nos filmes] é uma maneira de se apropriar do texto. Isso passa pelo seu corpo. A palavra passa por seu corpo" (p. 103-104).
} 
O modo demonstrativo presente na forma como os personagens recitam os seus textos, e que, por sua vez, caracteriza a natureza didática pelo qual a fita procura conduzir o espectador para a narrativa proposta, não é por demais insistir, tornar-se uma marca presente em toda encenação da película La Chinoise, além do fato de que sinaliza para os procedimentos retóricos utilizados pelos professores durante suas preleções em cursos, conferências, aulas e seminários.

De acordo com o sociólogo francês Jean-Pierre Esquenazzi (2004), a película La Chinoise propõe uma atribuição nos papéis dos atores que compreende três aspectos: entrevistas, atrações e conversações. As conversações nos interessam de perto, visto que elas, conforme propõe o autor, "tornam-se essencialmente demonstrativas: cada personagem deriva em geral por afirmação didática com o objetivo de convencer seu ou seus interlocutores. O modelo habitual da conversação é, frequentemente, representado pelo do curso (p. 246)". Assim, conclui o autor, as "exposições magistrais são apresentadas sucessivamente a cada personagem (exceto Yvonne) diante dos seus camaradas". Não deixa de ser curiosa a manifestação desses gestos retóricos dos profissionais da educação em La Chinoise.

Uma película na qual se propunha dialogar com parte da imagética relacionada com a revolução (fotos de figuras da esquerda, símbolos como a foice e o martelo, cores como o vermelho, o discurso de ruptura que a pressupõe), fundamenta-se, no seu propósito de veicular sua mensagem sobre ela, nos procedimentos retóricos educacionais de ensino-aprendizagem. Seriam eles os únicos disponíveis e ao alcance da criação cinematográfica? Ou pode-se pressupor que tais procedimentos foram os mais adequados para o processo de ensino-aprendizagem da revolução encenada na fita? Em outros termos: como Godard fomenta sua criação cinematográfica? Tais indagações sinalizam para o caráter processual da obra cinematográfica de Jean-Luc Godard, ou seja, para os estímulos materiais e de análise mediante os quais ele se apoia tendo por fim sua obra fílmica, sendo necessário um breve panorama sobre esse aspecto.

\subsection{Godard: cinema e criação artística}

Antes de prosseguir na análise dos gestos dos profissionais da educação em La Chinoise, caberia, nesta seção, interpretar a epígrafe que norteia este estudo sobre essa película: "Não se filma senão o passado, quer dizer o que se passa. E são sais de prata que fixam a luz" (Godard, Historie (s) du cinéma, parte 3A). Ela parece sinalizar para uma pretensão do cineasta em captar o instante imediato do seu contexto (o fazer artístico imediato é contemporâneo aos fatos que são vividos), reconhecendo, ao mesmo tempo, os limites e o alcance da atividade cinematográfica. 
Diante do fato de que se torna necessário não confundir as declarações do cineasta que têm por objetivo autojustificar sua posição política ou cinematográfica perante o seu público ou meio profissional, temos que, embora sua fala tenha sido fundamentada na sua produção Historie(s) du cinéma (1988-1998), pode-se notá-la presente na entrevista aos Cahiers du cinéma (concedida após o lançamento de La Chinoise) no trecho que trata sobre o cinema e os problemas técnicos que os cineastas deviam se envolver: "Quando comecei a fazer cinema, só o pensava em termos de eternidade; agora considero-o, de fato, uma coisa efêmera" (BARBOSA, 1968, p. 136). A problemática do efêmero pode ser esclarecida pela posição do cineasta ante o papel do cinema. Ao comparar a política e o cinema, dois anos antes de concretizar La Chinoise, constatou que a política "é o presente e o passado" e o cinema detinha um papel, o seu "compromisso é com o presente" (BARBOSA, 1968, p. 96). Na mesma oportunidade, confessou a incapacidade de se abordar aquilo que não se conhecia anteriormente (p. 99), o que permite inferir a necessidade de um maior vínculo do cineasta com o meio na qual se vive.

A consciência efêmera do cinema, conjugada com a uma marca intervencionista foi notada pela ensaísta Susan Sontag (1987) na obra de Jean-Luc Godard.

O seu importante estudo sobre a obra godardiana ${ }^{14}$ é um indício da atração e recepção na qual a produção cinematográfica de Godard se inscrevia, perante a um conjunto diferenciado de pensadores e de estudantes norte-americanos, e, por outro lado, denota que as películas do cineasta foram concebidas, nas suas palavras, como um "organismo vivo" que habitam o "presente real":

Uma película [de Godard] é concebida como um organismo vivo: não tanto um objeto, mas uma presença ou um encontro - um evento plenamente histórico ou contemporâneo, cujo destino é ser transcendido pelos fatos futuros. Buscando criar um cinema que habite o presente real, Godard coloca regularmente em seus filmes referências a crises políticas atuais: a Argélia, a política interna de De Gaulle, Angola, a Guerra do Vietnã. [...] a história de Duas ou Três Coisas foi sugerida por uma reportagem especial publicada em Le Nouvel Observateur, sobre donas-de-casa nos novos conjuntos de apartamentos para famílias de baixa renda, que se tornaram prostitutas de tempo parcial para aumentar seus ganhos mensais. (SONTAG, 1987, p. 171-172).

\footnotetext{
${ }^{14}$ Este ensaio foi publicado no ano de 1968 por ocasião da exibição de filmes do cineasta em Berkeley e em demais cidades nos Estados Unidos.
} 
A ênfase de Godard em "criar um cinema que habite o presente real" possibilita uma maior inserção da obra godardiana junto a um público diverso, que distinguia, na sua cinematografia, um veio de identificação em relação a uma expectativa crescente de intervenção política e cultural na realidade entre os anos finais da década de sessenta.

Por sua vez, essa aproximação do cineasta a um "presente real" se estabelece mediada por um testemunho no qual parece inscrever seus estímulos e materiais de análise para a fatura cinematográfica. Em outros termos, o testemunho do "real" transparece para o cineasta sob a forma de entrevistas nas quais ele se apoia para a confecção de seus filmes; também as reportagens, as pinturas, as fotografias, e os sons (um "elemento vivo" na sua concepção ${ }^{15}$ ), o discurso político, a literatura, constituem um veio em que ele se apropria na fatura de suas fitas.

Cabe destacar que Jean-Luc Godard pertence a uma tradição artística que acredita na capacidade do cinema de testemunhar o real. Neste prisma, também a fotografia e a literatura, a pintura e o cinema, para Godard, partilhariam de uma mesma natureza, qual seja, nas palavras de Céline Scemama (2011): "o realismo fundamental da imagem" (p. 30). Contudo, ainda que haja um parentesco entre as artes motivado pela capacidade de "testemunhar o real", Godard compreende a ideia de que o cineasta ou o artista deixa a sua "marca" no objeto artístico que ele produz:

Esse parentesco entre as artes é resultado, fundamentalmente, dessa capacidade de testemunhar o real, fixando os pedaços de vida nos quais ele deixa sua marca. Está em jogo, aqui, toda uma tradição de pensamento sobre a arte, como, por exemplo, a de Wilde, para quem "a vida imita a arte muito mais do que a arte imita a vida", ou a de Proust em Em busca do tempo perdido. Uma concepção de arte que pode ser encontrada, igualmente, em Bazin. A capacidade que a fotografia tem de revelar o real não se deve a sua função de reprodutibilidade técnica, mas a sua beleza. Em outras palavras, tanto para Bazin, como para Wilde, Proust ou Godard, a novidade do olhar do artista se imprime necessariamente nos objetos, revelando-os. (SCEMAMA, 2011, p. 30-31).

\footnotetext{
${ }^{15}$ Jean-Luc Godard, ao comentar o caráter de "contraponto" e de "contradição" na qual parece incidir a música em seu filme Alphaville, defendeu a ideia de que a música em suas películas constituem um elemento da "narrativa", sendo que ela "evoca a vida, é a música do mundo exterior", e os sons em suas fitas "têm valor de imagens" (BARBOSA, 1968, p. 111). Desta forma, a música ou o som para Godard "é um elemento vivo, assim como a rua ou os automóveis. É uma coisa que descrevo, algo que já existe antes do filme” (p. 112).
}

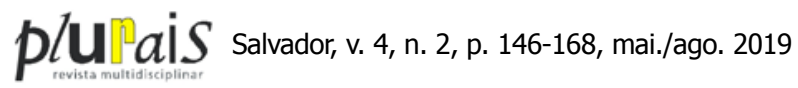


Não obstante um cinema que garante um papel e cujo "compromisso é com o presente" ou perante a ênfase, presente em Godard, em "criar um cinema que habite o presente real" (SONTAG, 1987), condições que não excluem uma marca de intervenção artística do cineasta no objeto artístico, tais circunstâncias não são o bastante para entender os gestos dos profissionais da educação que a fita La Chinoise insiste em representar na tela do cinema.

\subsection{Gestos da educação em La Chinoise: enunciados do discurso e gestos de atividade}

Jean-Pierre Esquenazi (2004) identifica em La Chinoise determinados procedimentos dos profissionais da educação que ele classifica como retóricos, ou seja, estão presentes na prática educacional dos professores ou no modo como determinados profissionais exercem o seu ofício de ensinar ou de ministrar cursos, palestras, conferências. Contudo o referido autor não procura interpretar o seu uso pelo cineasta ou suas implicações, limita-se a descrevê-los, cabendo a este estudo a tarefa de percebê-los como atos ou movimentos discursivos presentes nas práticas dos profissionais da educação sem os quais toda e qualquer interação verbal entre professores e alunos não seria possível.

Se, tal como definiu Mikhail Bakhtin/Volochínov (2014), a comunicação verbal não pode ser "compreendida e explicada fora" de um "vínculo com a situação concreta" e é por meio deste vínculo que a comunicação verbal é acompanhada dos "atos sociais de caráter não verbal" (p. 128) que acompanham a comunicação, estamos considerando que os gestos dos atores que encenam as práticas de profissionais da educação, inevitavelmente partem de uma base de orientação (dado pelo caráter da língua como "fato social") para a ação de linguagem encenada na película La Chinoise, entretanto conferem a estas práticas uma "aplicação individual" própria de cada ator.

Entretanto, o caráter da língua como "fenômeno social", em ocasião oportuna, permitiu a Mikhail Bakhtin a ampliação da sua reflexão sobre a linguagem com a consecução da noção de "gêneros do discurso" (2011), definição que proporciona entender os gestos dos profissionais da educação encenados no filme, bem como os destinatários dos discursos proferidos nos diálogos da fita.

Do conjunto de suas definições, infere-se uma base de orientação na qual o discurso se reveste, e presume-se, a partir das pesquisas encaminhadas por Mikhail Bakhtin sobre a comunicação verbal e o seu caráter interacionista, que também os gestos dos profissionais da educação, constituídos por "movimentos discursivos" e "pragmáticos observáveis no desenvolvimento das atividades didáticas" (NASCIMENTO, 2012, p. 16), obedecem a uma mesma base de orientação geral, sem a qual os profissionais do ensino não se reconheceriam, 
ou, a partir deles, estes profissionais fundamentam as suas práticas de ensino em sala de aula, observando a aplicação individual de cada um no seu ofício.

É nesse quadro que se pode falar em "gêneros de atividade" (FAÏTA, 2004, p. 57-80), que se referem a "formas de fazer que impregnam nossas formas de ação" (p. 60) e a que nos reportamos para elucidar determinadas cenas da película La Chinoise, pois, se tais formas de fazer são reconhecidas pelos profissionais de ensino ${ }^{16}$ e constituem uma base de orientação geral para a sua prática, é plausível supor que serviram como referência para a composição da de partes da fita, visto que podem ter ancorado o cineasta e os atores na composição delas, ilustrada com base em sua própria experiência na condição de indivíduos partícipes de situações que envolveram a manifestação daqueles profissionais em diferentes práticas de ensino e aprendizagem por eles vivenciadas ou mesmo por eles observadas ou por eles executadas.

Assim, os movimentos do corpo do ator na cena (um dedo em riste, a inclinação do tronco, o fato de estar sentado ou de pé, a posição das mãos junto às anotações ou sobre a mesa, a variação do olhar devotando acumpliciamento ou repreensão, a mão dentro do bolso ou com um cigarro entre os dedos, o menear com a cabeça asseverando algo ou contestando-o) se assemelham, pois, a outras formas de fazer dos professores na sala de aula, em que o movimentar-se em cena (ou na sala de aula) torna-se um imperativo a se perseguir, instituído a partir dos gêneros de atividades dos profissionais de ensino. Também as atividades propostas nas cenas pelos personagens (o gênero "exposição" é a condição para que haja a possibilidade de "participação" dos ouvintes; e é também a condição para que "pratique-se a teoria" anteriormente vista ${ }^{17}$ : um esquete sobre o tema abordado) se enquadram no perfil das práticas daqueles profissionais.

\footnotetext{
${ }^{16}$ Maria Elvira do Nascimento descreve algumas dessas formas no seu ensaio sobre os gêneros da atividade, gêneros textuais: "[...] consideramos os movimentos sucessivos pelos quais o professor conduz a sua aula como gêneros de atividades que são reconhecidos pelos professores que dão a eles diferentes denominações, como por exemplo: "revisão de prova com os alunos", "discussão de um problema", "discussão do grupo a partir da leitura crítica", "montagem de um painel", "recorte e colagem de figuras decorativas" ou simplesmente "aula de produção de texto", "aula de leitura", "aula expositiva" etc. O fato de que essa atividades são compartilhadas entre os professores e são reconhecidas por constituírem formas estabilizadas do seu agir profissional, permite que se fale de gêneros de atividades como sendo gêneros de discurso que existem, construtos sócio históricos independentes do locutor que age discursivamente por eles em um determinado momento" (NASCIMENTO, 2009, p. 56, grifo do autor).

${ }^{17} \mathrm{O}$ terrorismo como "exercício" revolucionário é uma das formas de colocar em prática a teoria que o grupo acolheu em seus estudos.
} 
Uma cena talvez ilustre tais práticas encenadas pelos atores. Na lousa, encontra-se Guillaume, que escreve o título da palestra a ser proferida por Omar: que representa a si mesmo Omar Diop, um militante político. Sua preleção se baseia em textos do filósofo Louis Althusser e do Pequeno Livro Vermelho, com trechos escolhidos da obra de Mao Zedong: Les perspectives de la gauche europpénne. Ele se posiciona de frente para a lousa e sublinha a palavra europpénne com um giz colorido, enquanto na banda sonora: a Rádio Péquim fornece as notícias sobre o movimento estudantil e sua luta revolucionária "contra o "colarinho branco" que se espalha entre os trabalhadores e camponeses". A "palestra" é a condição para que haja o "debate" e todo o conjunto de ações representa um gênero do discurso. Uma curta apresentação marca o seu início, e coube a Véronique essa tarefa: "Omar um camarada do círculo filosófico de Nanterre. É o suficiente!". Antes mesmo de terminar a apresentação, o personagem Omar já havia disposto suas anotações sobre a mesa.

À medida que o personagem desenvolve sua palestra, surge a imagem dos quatros militantes ao redor de uma pilha de livros vermelhos.

A terceira parte da preleção de Omar é iniciada com o som de um xilofone. Antes de começar a sua fala, Omar meneia a cabeça de um lado a outro e olha para seus interlocutores. Ao mencionar a morte de Stálin pela segunda vez, surge uma foto dele com os seus olhos rabiscados de vermelho, o que lhe confere um aspecto malicioso ou maligno. Num dos trechos do discurso de Omar, a câmera, em panorâmica de cima para baixo, faz o enquadramento do seu corpo com as mãos sobre a mesa. $\mathrm{O}$ foco é a mesa com trechos do texto e vários objetos: um livro aberto, o giz colorido, um maço de cigarros, um exemplar dos Cahiers Marxiste-leniniste, e o livro vermelho de Mao. A sua fala pode ser entendida como um gênero do discurso ${ }^{18}$.

Considerando que os enunciados discursivos, tal como definiu Mikhail Bakhtin (2011), são plenos de tonalidades dialógicas (p 298, grifo no original), ou seja, constituem uma "resposta aos enunciados precedentes de um determinado campo" (p. 297), e mesmo o enunciado mais "monológico" não deixa de ser uma "resposta àquilo que já foi dito sobre dado objeto, sobre dada

\footnotetext{
${ }^{18}$ Jean-Luc Godard procurou mediar a fala do personagem com fotos que conferem ao enunciado discursivo do personagem uma tônica que revela parte dos interlocutores a qual se destina a argumentação: 'A morte de Stálin nos deu o direito de contar exatamente o que possuímos, de chamar a riqueza e a indigência pelos seus verdadeiros nomes, de pensar e falar de nossos problemas e conduzir pesquisas sérias. [Neste ponto, surge uma foto de Mao] A morte de Stálin nos permitiu de escapar, em parte, de nosso provincianismo teórico, de conhecer [Kirilov é enquadrado consertando o guidão da bicicleta com uma ferramenta]. e reconhecer a existência de outros além de nós mesmos e, desta forma, conhecer melhor a nós mesmos, conhecer o lugar que ocupamos no conhecimento e na ignorância do marxismo, e, assim, começar a nos conhecer. [Plano americano de Omar, e portanto, mais próximo do espectador da fita]. A nossa tarefa de hoje é simplesmente enfrentar e solucionar estes problemas para dar um pouco de existência e consistência teórica à filosofia marxista. Tereis perguntas a fazer?" (GODARD, 1973, p. 345-346).
} 
questão" (p. 298), temos que a fala do personagem Omar, fazendo uso, em sua preleção, do discurso de outra pessoa, reúne uma apreciação da morte de Josep Stálin com um tom solene de convite ao autoconhecimento de si e do outro e conclui com o estabelecimento de uma ação que ponha em prática aquela convocação, que tem por objetivo referendar e dar consistência teórica à filosofia marxista. Em suma, o enunciado pronunciado por Omar avalia, convoca e determina o que se deve fazer: a revolução!

Ao fazê-lo, indiretamente, presume-se a que interlocutores a película La Chinoise se dirige, pois, conforme Mikhail Bakhtin (2011), "um traço essencial (constitutivo) do enunciado é o seu direcionamento a alguém, o seu endereçamento" (p. 301, grifo no original): a esquerda revolucionária, que pretendia estabelecer a revolução por meio das armas e desejava um alinhamento com o maoísmo chinês; a esquerda latino-americana, principalmente, uma vertente pró-cubana ventilada pela brisa revolucionárias provenientes de Cuba a partir de 1959; os estudantes universitários franceses partidários de mudanças no sistema educacional do seu país.

Outra sequência pode ser descrita como exemplo dos gestos de atividade. Guillaume entra na sala e olha pra todos os presentes: ele irá dissertar sobre "Problémes d'information/ Por une TV. Republicaine". Abre a porta, traz consigo algumas folhas, está de gravata. Olha para os colegas e começa: "camaradas e amigos". Pega o maço de cigarros e retira um deles, mencionando o tema que será abordado: "falaremos sobre as Atualidades". A forma como se dirige para os demais colegas da célula é pontuada por meneios na cabeça, sendo que as mãos estão apoiadas sobre a mesa. $\mathrm{O}$ tom cerimonioso da fala tem por objetivo envolver o público ao qual se dirige o personagem: o espectador. Depois que termina a exposição, faz indagações com o propósito de inquirir os presentes sobre uma "participação". Com a suas abordagens, que requeriam as respostas dos colegas, investe aos gritos por duas vezes junto a eles, procurando incitá-los a "uma resposta".

A sutileza marca a cena. Nela, não vemos na tela o militante travestido de professor ou de palestrante aos berros contra os ouvintes. Apenas assistimos ao efeito de suas palavras sobre os demais, que, assustados, procuram responder às suas indagações. A digressão a outra película, Les quatre cents coups (Os incompreendidos, 1959), de François Truffaut, torna-se inevitável, pois notase um desejo de permuta ou de tonalidade dialógica de papéis dos personagens de forma a sinalizar para uma outra "situação concreta" de inserção na realidade.

Estaria, pois, Jean-Luc Godard, estabelecendo os marcos de uma ruptura com os seus colegas de Nouvelle Vague, ao propor tal representação ${ }^{19}$ ?

\footnotetext{
${ }^{19}$ Há indícios que levam a crer que François Truffaut não concordava com a representação exigida do ator Jean-Pierre Léaud, por Godard, em distintos filmes, a partir de Masculino-feminino. E o processo de ruptura definitiva dos dois cineastas decorre após esta película filmada no mesmo ano em que La Chinoise (BAECQUE, 2010, b, p. 310).
} 


\section{Considerações finais}

No que diz respeito à educação, em La Chinoise, embora os personagens não encenem os papéis de professores na fita, a sua prática, estabelecida pelos movimentos do corpo dos atores nas cenas, foram interpretados como atos ou movimentos discursivos que estão presentes no uso daqueles profissionais de ensino.

Nesse tocante, os gestos profissionais percebidos nos personagens em La Chinoise, e não é por demais repetir, se apoia na reflexão estabelecida por Mikhail Bakhtin/Volochínov (2014), segundo a qual a língua é um fato social ("produto de uma criação coletiva" p.81), ou seja, a língua para esse autor é entendida como um "conjunto de formas", cujo os indivíduos estão imersos e que garantem a comunicação verbal entre eles, porém este conjunto confere a cada um a "aplicação individual de uma forma dada no ato de fala única" (p. 80).

Para este autor a comunicação verbal não pode ser "compreendida e explicada fora" de um "vínculo com a situação concreta". Nas suas palavras:

Graças a esse vínculo concreto com a situação, a comunicação verbal é sempre acompanhada por atos sociais de caráter não verbal (gestos do trabalho, atos simbólicos de um ritual, cerimônias, etc.), dos quais ela é muitas vezes apenas o complemento, desempenhando um papel meramente auxiliar. (BAKHTIN/ VOLOCHÍNOV, 2014, p. 128).

\footnotetext{
O papel protagonizado por Jean-Pierre Léaud e personificado em Guilhaume, em La Chinoise, é uma inversão em partes daquele em que interpretou Antoine Doinel, o adolescente desorientado face o ambiente autoritário da escola e a desatenção dos pais . Apesar da inversão dos papéis, de aluno castigado e humilhado pelo professor para a condição de militante-professor, que incide sobre seus camaradas, o protagonista não descura de um teor de arrogância e de agressividade na sua fala, condição que também estavam presentes na atmosfera do professor que castigara Antoine Doinel. Portanto, se a distância temporal compele para que estes dois personagens se afastem, a atmosfera que recobre suas ações (a repreensão e o "castigo" de Doinel pelo mestre de aula; a "exposição" e o grito de Guilhaume) contribuem para que haja uma confluência entre eles. Após a "exposição" que requer uma "resposta" dos ouvintes, a sequência apresenta Guilhaume, desta vez, sentado, e notamos, mais uma vez, na maneira como conduz a atividade, traços daqueles procedimentos e de enunciados do discurso que congregam os profissionais da educação: neste caso, o personagem pretende que os demais proponham o tema que servirá de "exemplo" para ilustrar a "teoria" supostamente aprendida. Sobre a mesa, estão dispostos vários óculos de sol. Ao fundo, na lousa, está uma página do jornal Garde Rouge. Guilhaume está com um cigarro entre dos dedos. Ele afirma que, numa informação, é preciso analisar o problema em seus diferentes aspectos. E olha para os integrantes da sala, quase sorrindo. "Chega de teoria". "Vamos a um problema prático!". Propõe que os demais participantes decidam o tema sem que se veja-os em cena: Véronique sugere: a Guerra; Henri sugere a região: a Ásia. Guillaume propõe então: o Vietnã, como "exemplo".).
} 
Portanto, os gestos dos profissionais da educação, manejados pelos atores, sinalizam para uma aproximação da película com a educação que é entendida como um processo de formação dos indivíduos, sendo empregada pelos personagens, e tendo por objetivo impelir, insuflar os integrantes da célula de estudos Aden Arábia rumo à ação revolucionária mediante o terrorismo, prática levada a cabo por determinado personagens da fita e que fatalmente os levará ao fracasso de tal empreitada.

\section{REFERÊNCIAS}

A RELIGIOSA. Direção : Jacques Rivette. França : Georges de Beauregard, 1965. 134 min, cor.

AUMONT, Jacques. Jacques Aumont. In: COUTINHO, Mário Alves (Org.). Godard, cinema, literatura (entrevistas). Belo Horizonte: Crisálida, 2013. pp. 29-55.

BAECQUE, Antoine de. Cinefilia: invenção de um olhar, história de uma cultura (1944-1968). Trad. São Paulo: Cosac Naify, 2010a.

.Godard: biographie. Paris: Grasset, 2010 b.

BAKHTIN, Mikhail. Os gêneros do discurso. In: Estética da criação verbal. Trad. Paulo Bezer-

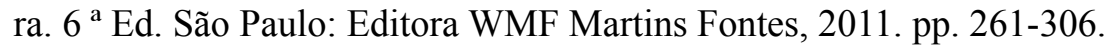

.; VOLOCHÍNOV, V. N. Marxismo e filosofia da linguagem: problemas fundamentais do método sociológico da linguagem. Trad. Michel Lahud et al. $16^{\text {a }}$ Ed. São Paulo: 2014.

BARBOSA, Haroldo Marinho. Jean-Luc Godard. Rio de Janeiro: Record, 1968.

BERGALA, Alain. Alain Bergala. COUTINHO, Mário Alves (Org.). Godard, cinema, literatura (entrevistas). Belo Horizonte: Crisálida, 2013. pp. 81-105.

COUTINHO, Mário Alves (Org.). Godard, cinema, literatura (entrevistas). Belo Horizonte:

Crisálida, 2013.

DANEY, Serge. O therrorisado (pedagogia godardiana). In: A rampa: Cahiers du cinéma, 19701982. Trad. Marcelo Rezende. São Paulo: Cosac Naify/Mostra Internacional de Cinema, 2007. pp. 107-114.

ESQUENAZI, Jean-Pierre. Godard et la société française des années 1960. Paris: Armand Colin, 2004.

FAÏTA, Daniel. Gêneros de discurso, gêneros de atividade, análise da atividade do professor. In: MACHADO, Anna Rachel (Org.). O ensino como trabalho: uma abordagem discursiva. Londrina: EDUEL, 2004. pp. 56-78. 
FERREIRA, Aurélio Buarque de Holanda. Novo dicionário Aurélio da Língua Portuguesa. ${ }^{\mathrm{a}}$ ed. Rio de Janeiro: Nova Fronteira, 1986.

GODARD, Jean-Luc. Cinco Guiones. Trad. Miguel Marías. Madrid: Alianza Editorial, 1973.

HAYDT, Regina Célia Cazaux. Didática e filosofia. In : Curso de didática geral. $7^{\mathrm{a}}$ ed. São Paulo: Ática, 2000. pp. 11-28.

HISTOIRE (S) DU CINÉMA. Direção de Jean-Luc Godard. França. Produtor: Canal+,Gaumont, 1988-1998. 258 m, cor.

LA CHINOISE. Direção de Jean-Luc Godard. Moema: Silver Screen Collection, 1967. 96 m, cor.

MARIE, Michel. A Nouvelle Vague e Godard. Trad. Eloisa A. Ribeiro et al. Campinas: Papirus, 2011.

MAYOR, Ana Lucia Soutto (Org.). Godard e a educação. Belo Horizonte: Autêntica, 2013

NASCIMENTO, Elvira Lopes. Gêneros da atividade, gêneros textuais: repesando a interação em sala de aula. In: NASCIMENTO, Elvira Lopes (Org.). Gêneros textuais: da didática das línguas aos objetos de ensino. São Paulo: Editora Claraluz, 2009. p. 51-90.

OS INCOMPREENDIDOS. Direção de François Truffaut. França. Produtor : François Truffaut, 1959. $100 \mathrm{~m}, \mathrm{p} / \mathrm{b}$.

PIERROT LE FOU. Direção de Jean-Luc Godard. França. Produtor: Georges de Beuregard,Dino De Laurentiis, 1965. $112 \mathrm{~m}$, cor.

PUPPO, Eugenio. ARAÚJO, Mateus (Org.). Godard inteiro ou o mundo em pedaços. São Paulo: Centro Cultural do Banco do Brasil, 2015.

RANCIÈRE, Jacques. O vermelho de A Chinesa: política de Godard. In: A fábula cinematográfica. Trad. Christian Pierre Kasper. Campinas: Papirus, 2013. (Coleção Campo Imagético), pp. 147-155.

SARLO, Beatriz et al. Jean-Luc Godard: el pensamiento del cine, cuatro miradas sobre Histoire(s) du cinéma. Buenos Aires: Paidós, 2003.

SCEMAMA, Céline. Para onde vai Godard... Na companhia de Orfeu, de Virgílio, e do anjo da história, um olhar para o passado. In: SERAFIM, José Francisco (Org.). Godard, imagens e 
memórias: reflexões sobre História (s) do cinema. Salvador: EDUFBA, 2011. pp. 21-90.

SERAFIM, José Francisco (Org.). Godard, imagens e memórias: reflexões sobre História(s) do cinema. Salvador: EDUFBA, 2011.

STAM, Robert. O espetáculo interrompido: literatura e cinema de desmistificação. Trad. José Eduardo Moretzsohn. Rio de Janeiro: Paz e Terra, 1981.

SONTAG, Susan. Godard. In: A vontade radical: estilos. Trad. João Roberto Martins Filho. São Paulo: Companhia das Letras, 1987. pp. 143-182.

VASCONCELOS, Jorge. A Pedagogia da Imagem: Deleuze, Godard - ou como produzir um pensamento do cinema. In: Educação \& Realidade. Porto Alegre, 33 (1), janeiro-junho de 2008. pp. $155-168$.

VIVRE SA VIE. Direção de Jean-Luc Godard. França : Imovosion DVD, Cinema e Arte, 1962. $80 \mathrm{~m}, \mathrm{p} / \mathrm{b}$.

ZEDONG, Mao. O Livro vermelho. Trad. Edições em Línguas Estrangeiras Pequim 1972. São Paulo: Martin Claret, 2004.

Enviado em: 26 de janeiro de 2019

Apreciado em: 02 de março de 2019

Inserido em: 08 de abril de 2019 